\title{
How to Excite Reader Interest
}

COMMUNICATION CORNER No. 27

\author{
by Philip Yaffe
}

Editor's Introduction

Each "Communication Corner" essay is self-contained; however, they build on each other. For best results, before reading this essay and doing the exercise, go to the first essay "How an Ugly Duckling Became a Swan," then read each succeeding essay.

Unless under duress, such as a school assignment or work assignment, people will read only what they want to. However, many will read at least the first couple lines before saying yes or no. Here are five techniques that greatly increase the chances they will say yes. 


\title{
How to Excite Reader Interest
}

\author{
COMMUNICATION CORNER No. 27
}

\section{by Philip Yaffe}

In the previous essay about making a microcosm into a universe, it was stated that the expository writing attitude counsels "no one wants to read what you are going to write." If you have fully accepted this idea, then you have also accepted that the writer's first task, before anything else, is to give readers reasons to read. There are several ways of doing this. Here are five of them:

1. Ask questions

2. Suggest a contrast or paradox

3. Write a newspaper-type lead

4. Personalize the situation

5. Start with an intriguing quotation

The following examples show the beginning of an extensive article on hay fever. Note once you get beyond the lead (first few paragraphs), the remaining information in all five versions is exactly the same.

\section{ASK QUESTIONS}

Few people can resist trying to see if they know the answer to a question. This introduction asks three questions about hay fever. Readers who are not certain about an answer-or certain they don't know the answer-are likely to be motivated to read further.

Did you know that hay fever is not a fever? That it has essentially nothing to do with hay? And that it is much more common in cities than in the countryside?

In short, the term "hay fever" is very misleading. As every sufferer knows, the symptomssneezing, runny nose, itchy and watering eyes, etc. - more closely resemble a cold than they do a fever. The French come closer to the truth by calling it "hay cold" (rhume des foins).

Also as every sufferer knows, hay fever is an allergic reaction to pollen, the fine powder that plants disperse in the wind as part of their reproductive cycle. It can be triggered by the pollen of any number of plants, including weeds, grasses, and trees. In Scandinavia, the culprit is most often birch; in the United Kingdom, grass; and in southern Europe, olive and cypress trees. The leading trigger for hay fever in the United States is ragweed. 
For these and other reasons, doctors refer to hay fever as "seasonal rhinitis" when it affects mainly the nose, or "seasonal rhino-conjunctivitis" when it affects both the eyes and nose.

The pollen origin of hay fever was first demonstrated in 1873 by Dr. Charles Blackley, himself a hay fever sufferer. The affliction is commonly called hay fever because the annual outbreak of symptoms for many allergic persons coincides with the hay harvest.

But if hay fever is caused by pollen, why should it be more common in cities than in the countryside?

The reasons are rather complex, but some observers believe it is a direct consequence of the Industrial Revolution. Before the 18th century, very little mention was made in the medical literature of hay fever. However, as rural populations became urbanized, hay fever became increasingly prevalent. Today it is believed to affect from 10-12 percent of the populations in Europe and North America, largely in cities.

Knowing the source of an illness is the first step towards finding an effective treatment. However, it is also necessary to know how it produces its symptoms.

(The story continues ...)

\section{SUGGEST A CONTRAST OR PARADOX}

The terms "contrast" and "paradox" are closely related.

A "contrast" is something that is commonly accepted as true but may not be so, or is at the extreme ends of a continuum (e.g. kilograms versus milligrams, mountains versus molecules, millennia versus minutes, etc.).

A "paradox" is something that appears to be impossible.

Hay fever is one of the most debilitating-and one of the most misnamed-of the so-called "minor medical conditions."

It is so debilitating because the annual attack (April-August in the Northern Hemisphere) can greatly disrupt the victim's ability to study or work. It also brings misery and isolation during the spring and summer, the two most "sociable" seasons of the year. It is so misnamed because the term "hay fever" is misleading. As every sufferer knows, the symptoms - sneezing, runny nose, itchy and watering eyes, etc.-more closely resemble a cold than they do a fever. The French come closer to the truth by calling it "hay cold" (rhume des foins). 
Another reason for disavowing the term: The name "hay fever" suggests that it is an illness of the countryside. The reality is, hay fever is much more common in cities. In fact, some observers believe it is a direct consequence of the Industrial Revolution.

Before the 18th century, very little mention was made in the medical literature of hay fever. However, as rural populations became urbanized, hay fever became increasingly prevalent. Today it is believed to affect from 10-12 percent of the populations in Europe and North America, largely in cities.

Finally, hay fever is only indirectly related to hay. It can be triggered by any number of plants, including weeds, grasses, and trees. In Scandinavia, the culprit is most often birch; in the United Kingdom, grass; and in southern Europe, olive and cypress trees. The leading trigger for hay fever in the United States is ragweed.

For these and other reasons, doctors refer to hay fever as "seasonal rhinitis" when it affects mainly the nose, or "seasonal rhino-conjunctivitis" when it affects both the eyes and nose.

Seasonal rhino-conjunctivitis is in fact an allergic reaction to pollen, the fine powder that plants disperse in the wind as part of their reproductive cycle. The pollen origin of hay fever was first demonstrated in 1873 by Dr. Charles Blackley, himself a hay fever sufferer. The affliction is commonly called hay fever because the annual outbreak of symptoms for many allergic persons coincides with the hay harvest.

Knowing the source of an illness is the first step towards finding an effective treatment. However, it is also necessary to know how it produces its symptoms.

(The story continues ...)

\section{WRITE A NEWSPAPER-TYPE LEAD}

You may not know what will interest an individual reader. However, by putting a lot of clear, concise, dense information right at the beginning (lead) of your text, you can be virtually certain that every reader will find something to attract his or her attention.

Hay fever, hardly known to our great-great-grandparents, today affects up to 12 percent of people in Europe and North America, and the trend is still upwards. Although considered a "mild medical condition," the watery eyes, runny nose, incessant sneezing, etc. for several months each year can be extremely debilitating for both social and economic life.

Absenteeism and reduced productivity in Europe and North America cost business an estimated $\$ 4.2$ billion annually, a burden that is expected to rise to $\$ 6.8$ billion by the end of the decade. 
The term "hay fever" is in fact very misleading. As every sufferer knows, the symptomssneezing, runny nose, itchy and watering eyes, etc. - more closely resemble a cold than they do a fever. The French come closer to the truth by calling it "hay cold" (rhume des foins).

Also as every sufferer knows, hay fever is an allergic reaction to pollen, the fine powder that plants disperse in the wind as part of their reproductive cycle. It can be triggered by the pollen of any number of plants, including weeds, grasses and trees. In Scandinavia, the culprit is most often birch; in the United Kingdom, grass; and in southern Europe, olive and cypress trees. The leading trigger for hay fever in the United States is ragweed.

For these and other reasons, doctors refer to hay fever as "seasonal rhinitis" when it affects mainly the nose, or "seasonal rhino-conjunctivitis" when it affects both the eyes and nose.

The pollen origin of hay fever was first demonstrated in 1873 by Dr. Charles Blackley, himself a hay fever sufferer. The affliction is commonly called hay fever because the annual outbreak of symptoms for many allergic persons coincides with the hay harvest.

But if hay fever is caused by pollen, why should it be more common in cities than in the countryside?

The reasons are rather complex, but some observers believe it is a direct consequence of the Industrial Revolution. Before the 18th century, very little mention was made in the medical literature of hay fever. However, as rural populations became urbanized, hay fever became increasingly prevalent. Today it is believed to affect from 10-12 percent of the populations in Europe and North America, largely in cities.

Knowing the source of an illness is the first step towards finding an effective treatment. However, it is also necessary to know how it produces its symptoms.

(The story continues ...)

\section{PERSONALIZE THE SITUATION}

There's a newspaper adage that says: One person killed in an earthquake is a tragedy; a thousand persons killed in an earthquake is a statistic. People like to hear about other people, as individuals. Therefore, if you can personalize a situation, you will gain reader interest.

When Mary woke up that morning, the birds were singing, the sun was shining and the sky was blue. Just the sort of day that makes you want to say, "It's good to be alive." She then noticed a slight yellowish haze in the sky, so instead she said, "I wish I were dead!" 
The haze was pollen; the hay fever season had started. Instead of the promise of a wonderful day, Mary now faced the certainty of sneezing, a runny nose, itchy and watering eyes, and other symptoms associated with her annual allergic disease.

She was not alone. Each year, more and more people suffer from hay fever. Hardly known to our great-great-grandparents, today it affects up to 12 percent of people in Europe and North America, and the trend is still upwards.

Although considered a "mild medical condition," hay fever can be extremely detrimental because the annual attack (April-August) can greatly disrupt the victim's ability to study or work. It also brings misery and isolation during the spring and summer, the two most "sociable" seasons of the year.

Hay fever really shouldn't be called hay fever. As every sufferer knows, the sneezing, running nose, itchy and watering eyes, and other discomforts the disease engenders more closely resemble a cold than they do a fever. The French come closer to the truth by calling it "hay cold" (rhume des foins). This is one reason doctors prefer to call it "seasonal rhinitis" when it affects mainly the nose, or "seasonal rhino-conjunctivitis" when it affects both the eyes and nose.

Medical practitioners also disavow the name because "hay fever" suggests that it is an illness of the countryside. The reality is, hay fever is much more common in cities. In fact, some observers believe it is a direct consequence of the Industrial Revolution.

Hay fever is only indirectly related to hay. It can be triggered by any number of plants, including weeds, grasses and trees. In Scandinavia, the culprit is most often birch; in the United Kingdom, grass; and in southern Europe, olive and cypress trees. The leading trigger for hay fever in the United States is ragweed.

The pollen origin of hay fever was first demonstrated in 1873 by Dr. Charles Blackley, himself a hay fever sufferer. The affliction is commonly called hay fever because the annual outbreak of symptoms for many allergic persons coincides with the hay harvest.

Knowing the source of an illness is the first step towards finding an effective treatment. However, it is also necessary to know how it produces its symptoms.

(The story continues ...) 
Something that appears to be of little or no general interest can be made more vital by putting it into a broader political, cultural, social, economic, or philosophical context. The power of this technique can often be reinforced by introducing the subject with an appropriate quotation.

"A splinter in the finger can hurt more than a broken leg-if all you have is only a splinter in the finger."-Anonymous

It is very difficult to judge someone else's pain and discomfort, which is why to some people hay fever seems funny (non-sufferers) and to others it can be deadly serious (sufferers). Granted, the individual symptoms-sneezing, runny nose, itchy and watering eyes, etc.-by themselves are not devastating. However, their constant repetition over several months every year (April-August) can make life virtually unbearable.

To many hay fever sufferers, its classification as a so-called "minor medical conditions" seems grossly inadequate. Not only does its annual attack cause personal pain and discomfort, it can greatly disrupt the victim's ability to study or work. It also brings misery and isolation during the spring and summer, the two most "sociable" seasons of the year.

Hay fever really shouldn't be called hay fever at all; the symptoms more closely resemble a cold than they do a fever. The French come closer to the truth by calling it "hay cold" (rhume des foins). This is one reason doctors prefer to call it "seasonal rhinitis" when it affects mainly the nose, or "seasonal rhino-conjunctivitis" when it affects both the eyes and nose.

Another reason for disavowing the term: The name "hay fever" suggests that it is an illness of the countryside. The reality is, hay fever is much more common in cities. In fact, some observers believe it is a direct consequence of the Industrial Revolution.

Hay fever is only indirectly related to hay. It can be triggered by any number of plants, including weeds, grasses and trees. In Scandinavia, the culprit is most often birch; in the United Kingdom, grass; and in southern Europe, olive and cypress trees. The leading trigger for hay fever in the United States is ragweed.

The pollen origin of hay fever was first demonstrated in 1873 by Dr. Charles Blackley, himself a hay fever sufferer. The affliction is commonly called hay fever because the annual outbreak of symptoms for many allergic persons coincides with the hay harvest.

Knowing the source of an illness is the first step towards finding an effective treatment. However, it is also necessary to know how it produces its symptoms.

(The story continues...) 
In addition to the "Make a Microcosm into a Universe" technique discussed in the previous essay, of the others I particularly appreciate the contrast and paradox tactic. Here are a few illustrative examples.

- Perhaps the second most influential scientist of the 20th century, after Albert Einstein, died yesterday and almost no one noticed. Of course, Jack Kilby's name was hardly a household word. However, virtually every household-not to mention every shop, business office, factory and other aspect of human activity-has been fundamentally transformed by his work. Quite simply, Jack Kilby invented the integrated circuit, the ubiquitous "chip" without which modern society would simply be inconceivable.

- Ben Hunter is a television pitchman. On his daily broadcast, he sells insurance, real estate, reducing plans, floor wax, toilet bowl cleaners, and a whole supermarket of other items.

On Thursdays, he sells children.

It sounds harsh, but Mr. Hunter himself says that is precisely his job. As a daytime announcer for KTTV, a Los Angeles outlet of Metromedia, Inc., most of his time is spent sandwiching thin slices of old Doris Day and Rock Hudson movies between commercial messages. But every Thursday afternoon, the graying, rugged-looking announcer hosts a 15-minute program whose stars are parentless children. The idea is to get them adopted by viewers.

- After waiting 17 years to get it onto the launch pad, scientists were disappointed, but hardly surprised, that their scheduled space probe to Pluto had been delayed several hours due to poor weather.

- Being born, living, and then dying are immutable aspects of human existence. What is not immutable is the "quality of the journey" between the two endpoints, which is why such keen attention is paid to the possible teratogenic effects of different therapeutic drugs or combination of drugs. "Teratogenic" refers to how drugs taken by a pregnant woman might affect the fetus in her womb.

Note: The following lead was written in mid-2001, several months before the euro went into circulation as the European Union's new common currency. People were still using their national currencies (francs, deutschmarks, guilders, escudos, pesetas, etc.)

- The most anticipated event of 2002-introduction of the euro-already took place almost three years ago. 
This was the principal message of Alex Furaha to the 20th EuroEnterprise Forum. He was referring to the January 1, 2002 "launch" of the euro, the new common currency for 12 of the 15 countries of the European Union.

A leading government economist, Mr. Furaha stressed the euro became the official currency of the E.U. three years earlier, on January 1, 1999. Ever since that date, national currencies such as the French franc, German mark, Italian lira and the Spanish peseta have existed in name only-just waiting to disappear from the world's monetary stage.

"There has been no exchange rate between these currencies since 1999, when they all became a single currency. What we have now is a conversion rate, not an exchange rate, because the relationship among them is fixed. The fact that the bills and coins of the euro will be introduced on January 1 is only the obvious expression of this already established fact," he explained.

This legal and economic reality in no way detracts from the importance of what will happen on the first day of next year, nor the complexities of making it happen.

Together with the "microcosm to universe" technique explained in the previous essay, you now have six creative ways to draw readers and listeners into your subject. So go and be creative!

\begin{abstract}
About the Author
Philip Yaffe was born in Boston, Massachusetts, in 1942 and grew up in Los Angeles, where he graduated from the University of California with a degree in mathematics and physics. In his senior year, he was also editor-in-chief of the Daily Bruin, UCLA's daily student newspaper. He has more than 40 years of experience in journalism and international marketing communication. At various points in his career, he has been a teacher of journalism, a reporter/feature writer with The Wall Street Journal, an account executive with a major international press relations agency, European marketing communication director with two major international companies, and a founding partner of a specialized marketing communication agency in Brussels, Belgium, where he has lived since 1974. He is the author of more than 30 books, which can be found easily in Amazon Kindle.
\end{abstract}

DOI: $10.1145 / 3414066$ 